\title{
Mechanical/Enthesial Origin for Ankylosing Spondylitis Axial Involvement? Clues from a Therapeutic Viewpoint
}

\section{Bruce Rothschild*}

Department of Medicine, Northeast Ohio Medical University and Biodiversity Institute, University of Kansas, USA

\begin{abstract}
Choices for therapeutic intervention for ankylosing spondylitis have been traditionally predicated on its classification as a form of inflammatory arthritis. While this approach is effective for management of peripheral joint disease and may reduce back pain, the nature of axial joint disease is controversial. New information suggests that the latter is predominantly mechanical in nature (e.g., related to enthesial stresses) with any inflammation representing a part of the normal response to injury. Introduction of an extension exercise program, with modification of contributing aspects of activities of daily living, and avoidance of flexion activities usually resolved back discomfort and assures the best possible residual posture (as the spinal fusion progresses). No intervention is known to slow that process. Rheumatology perhaps started as codification empirical approaches. Approaching the axial involvement of ankylosing spondylitis as a mechanical phenomenon is not only clinically effective, but is also cost-effective, reducing the need for expensive biological agents.
\end{abstract}

The nature of axial skeleton involvement in ankylosing spondylitis is unclear. It is assumed by some to be an essentially inflammatory process, so much so that expensive biological therapies were considered and apparently result in significant improvement in back pain. It is unclear; however, if such agents alone alter the natural history of the disease, the propensity to vertebral fusion in positions that compromise lifestyle. Others have suggested stress or what Alphonse Masi calls "inate axial (spinal) myofascial hypertonicity" as the causes of eventual loss of motion. There is interesting clinical evidence to support the latter.

Keywords: Ankylosing; Axial skeleton; Spondylitis

\section{Axial Disease as Inflammatory?}

The role of inflammation in vertebral manifestations of ankylosing spondylitis has been controversial [1-5]. Inflammation has been interpreted as the source of the edema recognized in the vertebral [611] centra of some individuals with ankylosing spondylitis $[12,13]$. However, most syndesmophytes appear at sites without apparent inflammation and not all inflammatory lesions lead to syndesmophytes [14]. While syndesmophytes are not the only motion-limiting vertebral column alterations in ankylosing spondylitis [15], the zygapophyseal joints have not been sufficient analyzed to address the question of inflammation (other than erosive disease) at that site. Nitrous oxide, increased by injury [16], activates inflammatory cytokines and repair at sites of tendon insertion $[17,18]$ and likely has similar effects at sites of ligament insertion. Prostaglandins, bone morphogenic and Wnt proteins are essential in new bone formation, but not tumor necrosis factor [19]. Inhibiting the latter clearly has clinical benefit [20], but its inhibition is not essential to controlling the back pain of ankylosing spondylitis.

\section{Axial Disease as Enthesial?}

While a characteristic finding in peripheral joints of individuals with spondyloarthropathy [21-29], involvement of the annulus fibrosus could be considered a form of entheseal reaction. Inflammation or ossification at the site of insertion of tendons, ligaments, and joint capsules defines enthesophytes $[23,28,30,31]$. Definition, however, has been more facile than assessing its clinical significance. Indeed, Atkin et al. [32] suggested that the most common cause for ankle enthesophytes is trauma, while van der Linden [33] noted postural considerations. Clinical experience seems to support a similar perspective for axial involvement in ankylosing spondylitis.

\section{Therapeutic Approaches}

The perspective that vertebral column fusion was inevitable in ankylosing spondylitis [34] led to approaches that would minimize the resultant kyphosis. That would reduce the need for extraordinary surgery (e.g., vertebral "fracture," excision and repositioning) and prism glasses. Lifestyle modification was part of the standard approach, including encouraging alteration of activities, especially to reduced cervical flexion. Thus, it was recommended that televisions (and subsequently computer screens) be elevated and that afflicted individuals read papers held in a vertical, rather than horizontal position.

Simply emphasizing the potential effect of unchanged lifestyle has not been sufficiently effective to motivate, let alone reinforcement behavior modification. I therefore started a program which educated/ instructed afflicted individuals as to an extension exercise program and advised them to avoid all flexion activities. The extension exercise program was quite simple: Pushups against the comprising walls, when facing a corner, with their feet approximately 1-1/2 to 2 feet from the corner. They were advised to maintain their neck in an

*Corresponding author: Bruce Rothschild, Department of Medicine, Northeas Ohio Medical University and Biodiversity Institute, University of Kansas, Lawrence, KS 66006, USA, Tel: 785-615-1523, Fax: 785-594-2691; E-mail: bmr@ku.edu

Received January 15, 2014; Accepted February 21, 2014; Published February 24,2014

Citation: Rothschild B (2014) Mechanical/Enthesial Origin for Ankylosing Spondylitis Axial Involvement? Clues from a Therapeutic Viewpoint. J Arthritis 3 : 120. doi: $10.4172 / 2167-7921.1000120$

Copyright: (C) 2014 Rothschild B. This is an open-access article distributed unde the terms of the Creative Commons Attribution License, which permits unrestricted use, distribution, and reproduction in any medium, provided the original author and source are credited. 
extended position. Noting limited respiratory excursion complicating ankylosing spondylitis, they were also advised to exhale with arm extension and inhale with arm flexion. The results were remarkable, but initially short-lived. Investigating relapses, I discovered that afflicted individuals were feeling better, so they had also added back some of their previous behavior. It was thus discovered that flexion activities negated the benefits of the extension exercise program. The approach then became institution of the extensor exercise program, with advice to avoid all flexion activities.

Three decades ago, individuals with ankylosing spondylitis were referred to me for of radiation therapy because of unremittent, severe back pain. Noting that vertebral pain seemed to disappear once the vertebral column was completely fused, it was thought that accelerating fusion (by radiation therapy) would relieve the pain [12,35], but with a price. Mindful that leukemia often complicated (with a 20 year delay) such therapy $[12,35]$, it was with no little trepidation that they were accepted to my clinic. Reference is made to $\mathrm{x}$-ray therapy, not because it is still part of our armamentarium for ankylosing spondylitis, but rather to demonstrate the draconian approaches that patients and physicians once considered despite its toxicity. In the hope of diminishing their pain to a level that would not require radiation therapy, the extension exercise program (with avoidance of flexion activities) was instituted. Pain was not only reduced, but essentially eliminated in individuals afflicted by ankylosing spondylitis, with multiple decade-long pains, unresponsive to indomethacin and other NSAIDs. Imagine my relief at not having to pursue a therapy (radiation) with such known draconian effects. Eliminating the pain that once prompted such drastic intervention is the most impressive aspect of this simple exercise program.

\section{Mechanically-induced Secondary Inflammation}

The ontogeny of axial skeleton involvement in ankylosing spondylitis is mindful of the chicken and the egg. Although attempts have been made to divide enthesitis into non-inflammatory and inflammatory varieties, inflammation complicated even simple exercises in a rabbit model [36]. Is there a difference in the character of the peripheral skeletal enthesopathy occurring in spondyloarthropathy and that occurring in the general population (healthy individuals)? Macroscopic examination of the calcanei revealed no recognizable difference between individuals with spondyloarthropathy and otherwise healthy controls [37]. While Lopez-Bote et al. [38] interpreted such ankle lesions (in spondyloarthropathy) as erosions, their failure to demonstrate a correlation between clinical and radiological findings is also compatible with the interpretation that these lesions originally represented avulsion of fascia or tendons. Trauma or stress as Benjamin and McGonagle [7], Lories et al. [8], Masi [9,11] and McGonagle et al. [10] simulate new bone formation, in a response to injury (as demonstrated in rat arthritis) [20].

Feydy's study [13] is precisely on point. They demonstrated no significant difference in character of lesions in spondyloarthropathy, with one exception: bone edema. Perhaps bone edema may well be the response to acute or subacute enthesial stress, which resolves with chronicity? Sedimentation rates also appear inconsistent in patients with spondyloarthropathy. Sharafi et al. [39] suggested that attachment of fibers to endomysium was protective against injury [40]. AndarawisPuri et al. [41] suggest that a major factor in damage at tendon insertion sites is loss of the protective natural fibril crimp and viscoelastic dampening. This also seems a reasonable consideration for ligamentous attachments. Perhaps the mechanical injury is the precipitating factor for axial joint disease (zygopophyseal and costovertebral involvement excepted) in ankylosing spondylitis.

\section{Response to Empirical Observation has made Rheumatology Special}

Rheumatology started as a very empirical specialty and advances often were the results of unanticipated observations. The hypothesis was perhaps not as important as the approaches it suggested and what might be derived from them. What started as a program to reduce the progression of kyphosis in ankylosing spondylitis was recognized to significantly reduce back pain, even among individuals who did not have limited back motion. This essay is not a discussion of the pathophysiology of the disease. Rather, it presents an extremely effective treatment that usually obviates the requirement for expensive or exotic, unpalatable interventions. This effectiveness of this treatment incidentally confirms a major role of mechanical phenomenon in the pathophysiology of axial involvement in this disease [42].

\section{Conclusion}

If lifestyle/behavior modification is so effective in ankylosing spondylitis, perhaps the simple cost-effective approach offered herein would help to contain health care costs, one that does not disadvantage afflicted individuals. It seems time to try to dissect the disease we call ankylosing spondylitis to determine the extent of contribution by mechanical and inflammatory processes.

\section{References}

1. Van Tubergen A, Ramiro S, van der Heijde D, Dougados $M$, Mielants $H$, et al. (2012) Development of new syndesmophytes and bridges in ankylosing spondylitis and their predictors: a longitudinal study. Ann Rheum Dis 71: 518523

2. Baraliakos X, Listing J, Rudwaleit M, Sieper J, Braun J (2008) The relationship between inflammation and new bone formation in patients with ankylosing spondylitis. Arthritis Res Ther 10: R104.

3. Bennett AN, Rehman A, Hensor EM, Marzo-Ortega H, Emery P, et al. (2009) Evaluation of the diagnostic utility of spinal magnetic resonance imaging in axial spondylarthritis. Arthritis Rheum 60: 1331-1341.

4. Maksymowych WP, Chiowchanwisawakit P, Clare T, Pedersen SJ, Ã stergaard $M$ et al. (2009) inflammatory lesions of the spine on magnetic resonance imaging predicts the development of new syndesmophytes in ankylosing spondylitis: Evidence of a relationship between inflammation and new bone formation. Arthritis Rheum, 60:93-102.

5. Weber U, Hodler J, Kubik RA, Rufibach K, Lambert RG, et al. (2009) Sensitivity and specificity of spinal inflammatory lesions assessed by whole-body magnetic resonance imaging in patients with ankylosing spondylitis or recentonset inflammatory back pain. Arthritis Rheum 61: 900-908.

6. van der Heijde D, Machado P, Braun J, Hermann KG, Baraliakos X, et al (2012) MRI inflammation at the vertebral unit only marginally predicts new syndesmophyte formation: a multilevel analysis in patients with ankylosing spondylitis. Ann Rheum Dis 71: 369-373.

7. Benjamin M, McGonagle D (2001) The anatomical basis for disease localisation in seronegative spondyloarthropathy at entheses and related sites. J Anat 199 503-526.

8. Lories RJ, Luyten FP, de Vlam K (2009) Progress in spondylarthritis Mechanisms of new bone formation in spondyloarthritis. Arthritis Res Ther 11 221

9. Masi AT (2011) An added perspective on the 2009 SPARTAN and IGAS report: an innate axial myofascial hypertonicity. J Rheumatol 38: 2092-2094.

10. McGonagle D, Stockwin L, Isaacs J, Emery P (2001) An enthesitis based model for the pathogenesis of spondyloarthropathy. additive effects of microbial adjuvant and biomechanical factors at disease sites. J Rheumatol 28: 2155 2159 
Citation: Rothschild B (2014) Mechanical/Enthesial Origin for Ankylosing Spondylitis Axial Involvement? Clues from a Therapeutic Viewpoint. J

11. Masi AT, Nair K, Andonian BJ, Prus KM, Kelly J, et al. (2011) Integrative structural biomechanical concepts of ankylosing spondylitis. Arthritis 2011: 205904.

12. Smith PG, Doll $R$ (1982) Mortality among patients with ankylosing spondylitis after a single treatment course with $\mathrm{x}$ rays. Br Med J (Clin Res Ed) 284: 449460 .

13. Feydy A, Lavie-Brion MC, Gossec L, Lavie F, Guerini H, et al. (2012) Comparative study of MRI and power Doppler ultrasonography of the heel in patients with spondyloarthritis with and without heel pain and in controls. Ann Rheum Dis 71: 498-503.

14. Lacout A, Rousselin B, Pelage JP (2008) CT and MRI of spine and sacroiliac involvement in spondyloarthropathy. AJR Am J Roentgenol 191: 1016-1023.

15. Resnick D (2002) Diagnosis of Bone and Joint Disorders. Philadelphia: Saunders, 1023- 1081.

16. Cho NS, Hwang JH, Lee YT, Chae SW (2011) Tendinosis-like histologic and molecular changes of the Achilles tendon to repetitive stress: a pilot study in rats. Clin Orthop Relat Res 469: 3172-3180.

17. Szomor ZL, Appleyard RC, Murrell GA (2006) Overexpression of nitric oxide synthases in tendon overuse. J Orthop Res 24: 80-86.

18. Boileau C, Martel-Pelletier J, Moldovan F, Jouzeau JY, Netter P (2002) The in situ up-regulation of chondrocyte interleukin-1-converting enzyme and interleukin-18 levels in experimental osteoarthritis is mediated by nitric oxide. Arthritis Rheum, 46: 2637-2647.

19. Schett G, Rudwaleit M (2010) Can we stop progression of ankylosing spondylitis? Best Pract Res Clin Rheumatol 24: 363-371.

20. Schett G, Stolina M, Dwyer D, Zack D, Uderhardt S, et al. (2009) Tumor necrosis factor alpha and RANKL blockade cannot halt bony spur formation in experimental inflammatory arthritis. Arthritis Rheum 60: 2644-2654.

21. Ball J (1971) Enthesopathy of rheumatoid and ankylosing spondylitis. Ann Rheum Dis 30: 213-223.

22. Jacobs JC (1983) Spondyloarthritis and enthesopathy. Current concepts in rheumatology. Arch Intern Med 143: 103-107.

23. Nigel GA, SIT'AJ SL (1979) Enthesopathy, Clin Rheumatic Dis; 5:857-872.

24. Olivieri I, Gemignani G, Braccini G, Romagnoli C, Pasero G (1989) Isolated HLA-B27 associated peripheral enthesitis. J Rheumatol 16: 1519-1521.

25. Sebes JI (1989) The significance of calcaneal spurs in rheumatic diseases Arthritis Rheum 32: 338-340.

26. Mander M, Simpson JM, McLellan A, Walker D, Goodacre JA, et al. (1987) Studies with an enthesis index as a method of clinical assessment in ankylosing spondylitis. Ann Rheum Dis 46: 197-202.

27. Heuft-Dorenbosch L, Spoorenberg A, van Tubergen A, Landewé R, van ver Tempel H, et al. (2003) Assessment of enthesitis in ankylosing spondylitis. Ann Rheum Dis 62: 127-132.
28. de Miguel E, Cobo T, Muñoz-Fernández S, Naredo E, Usón J, et al. (2009) Validity of enthesis ultrasound assessment in spondyloarthropathy. Ann Rheum Dis 68: 169-174

29. D’Agostino MA, Said-Nahal R, Hacquard-Bouder C, Brasseur JL, Dougados M et al. (2003) Assessment of peripheral enthesitis in the spondylarthropathies by ultrasonography combined with power Doppler: a cross-sectional study. Arthritis Rheum 48: 523-533.

30. Nishikai M, Sugimoto M, Sato A, Takeuchi H (1986) Idiopathic periphera enthesopathy without spondylarthritis. Ann Rheum Dis 45: 774-775.

31. Resnick D, Niwayama G (1983) Entheses and enthesopathy. Anatomical, pathological, and radiological correlation. Radiology 146: 1-9.

32. Atkin SL, el-Ghobarey A, Kamel M, Owen JP, Dick WC (1990) Clinical and laboratory studies in patients with leprosy and enthesitis. Ann Rheum Dis 49: 715-717.

33. van der Linden SM (1990) Clinical and radiographic features of ankylosing spondylitis. Curr Opin Rheumatol 2: 563-569.

34. McCarty D (1989) Arthritis and Allied Conditions. 11th ed. Philadelphia: Lea \& Febiger, 934-943.

35. Rothschild BM (1982) Rheumatology: A Primary Care Approach. New York: Yorke Medical Press, 178-187.

36. Backman C, Boquist L, Fridén J, Lorentzon R, Toolanen G (1990) Chronic achilles paratenonitis with tendinosis: an experimental model in the rabbit. $J$ Orthop Res 8: 541-547.

37. Shaibani A, Workman R, Rothschild BM (1993) The significance of enthesopathy as a skeletal phenomenon. Clin Exp Rheumatol 11: 399-403.

38. López-Bote JP, Humbria-Mendiola A, Ossorio-Castellanos C, Padrón-Pérez M, Sabando-Suárez P (1989) The calcaneus in ankylosing spondylitis. A radiographic study of 43 patients. Scand J Rheumatol 18: 143-148.

39. Sharafi B, Ames EG, Holmes JW, Blemker SS (2011) Strains at the myotendinous junction predicted by a micromechanical model. J Biomech 44 2795-2801.

40. Lynch GS, Rafael JA, Chamberlain JS, Faulkner JA (2000) Contraction-induced injury to single permeabilized muscle fibers from $\mathrm{mdx}$, transgenic $\mathrm{mdx}$, and control mice. Am J Physiol Cell Physiol 279: C1290-1294.

41. Andarawis-Puri N, Sereysky JB, Jepsen KJ, Flatow EL (2012) The relationships between cyclic fatigue loading, changes in initial mechanical properties, and the in vivo temporal mechanical response of the rat patellar tendon. J Biomech 45: 59-65

42. van Tubergen A, Ramiro $S$, van der Heijde $D$, Dougados $M$, Mielants $H$, et al. (2012) Development of new syndesmophytes and bridges in ankylosing spondylitis and their predictors: a longitudinal study. Ann Rheum Dis 71: 518523 